\title{
HIGH FREQUENCY ULTRASOUND WAVES FOR DEGRADATION OF AMOXICILLIN IN THE PRESENCE OF HYDROGEN PEROXIDES FOR INDUSTRIAL PHARMACEUTICAL WASTEWATER TREATMENT
}

\author{
MATOUQ M., ${ }^{1, *}$ \\ TAGAWA T. ${ }^{2}$ \\ NII S. ${ }^{2}$
}

Received: $18 / 04 / 2014$

Accepted: 10/06/2014

Available online: $23 / 10 / 2014$
${ }^{1, *}$ Al-Balqa Applied University, Faculty of Engineering Technology Chemical Engineering Department P.O. Box 4486, Amman 11131, Jordan

${ }^{2}$ Department of Chemical Engineering Nagoya University Chikusa, Nagoya 464-8603, Japan

*to whom all correspondence should be addressed: e-mail: matouq3@yahoo.com

\begin{abstract}
Amoxicillin degradation with and without high frequency ultrasound waves of $2.4 \mathrm{MHz}$ has been investigated. The concentration of amoxicillin was selected to be similar to that of outlet wastewater effluent concentration in pharmaceutical industry namely 50 and $100 \mathrm{ppm}$. The application of ultrasound waves together with the addition of hydrogen peroxide $\mathrm{H}_{2} \mathrm{O}_{2}$ increased the rate of degradation of antibiotic amoxicillin. The doses of $\mathrm{H}_{2} \mathrm{O}_{2}$ used were $5,2,1$, and $0.1 \mathrm{ml}$ in a solution of $50 \mathrm{ml}$ of amoxicillin. The study showed that ultrasound waves and $\mathrm{H}_{2} \mathrm{O}_{2}$ had improved amoxicillin degradation. The ultrasound has improved the degradation rate more than two times in comparison to amoxicillin solution without ultrasound waves. This degradation rate has been achieved within 90 minutes.
\end{abstract}

Keywords: ultrasound, high frequency ultrasound waves, amoxicillin, degradations, antibiotics, pharmaceutical wastewater treatment, industrial wastewater, hydrogen peroxides, amoxicillin hydrogen peroxide reaction

\section{Introduction:}

The environmental impact of the pharmaceutical industry is generally attributed to the wastewater that was generated during the process. Pharmaceutical manufacturers generate process wastewater with a variety of conventional parameters (BOD, TSS, and $\mathrm{pH}$ ) and other additional chemical constituents. Process water includes any water that, during manufacturing or processing, comes into direct contact with or results from the use of any raw material or production of an intermediate, finished product, byproduct, or waste.

Process wastewater includes water that was used or formed during the reaction, water used to clean process equipment and floors, and pump seal water. Non-process wastewater includes non-contact cooling water (used in heat exchangers), non-contact ancillary water (boiler blow down, bottle washing), sanitary wastewater, and wastewater from other sources (storm water runoff).

Matouq M., Tagawa T. and Susumu N. (2014), High frequency ultrasound waves for degradation of amoxicillin in the presence of hydrogen peroxides for industrial pharmaceutical wastewater treatment, Global NEST Journal, 16(5), 805-813. 
The pharmaceutical residues have been detected in environmental samples including groundwater, surface water, and municipal wastewater. Pharmaceutical drugs given to people as well as to domestic animals include antibiotics, hormones, pain relievers, tranquilizers, and chemotherapy chemicals given to cancer patients. Many drugs are designed to be persistent and lipophilic, so that they can retain their chemical structure long enough to do their therapeutic work. These drugs are excreted and distributed into the environment by flushing toilets as well as by spreading manure and sewage sludge onto soil.

These chemicals persist in the environment, enter the food chain, bioaccumulate, biomagnify, and cause harmful effects to wildlife and humans. Because of aquatic pollution by these chemicals, bacteria and other microbes in the aquatic environment can become more resistant to these chemicals. This results in the development of more antibiotic resistant and virulent pathogens in the environment. Therefore, the persistence pharmaceutical chemicals in the environment have become a global problem. Another concern about antibiotic residues in the environment is the potential risk for aquatic and terrestrial organisms that exhibit resistance to some antibiotics. It has been reported that bacteria isolated from sewages showed resistance to antibiotics, such as ciprofloxacin, erythromycin and tetracycline (da Silva et al., 2006).

In general the numerous unit operations and processes to remove wastewater contaminants are grouped together to provide various levels of treatment. The treatment of water is divided into four parts:

1. Physical - primary methods are referred to physical or physical-chemical unit Operations, e.g., filtration, adsorption, air flotation, flocculation and sedimentation.

2. Biological - secondary referred to biological operations.

3. Chemical - advanced or tertiary referred to chemical or to combinations of all three e.g. Thermal oxidation (combustion), Chemical oxidation, lon exchange, Chemical precipitation, incineration. The use of conventional water and wastewater treatment processes becomes increasingly challenged with the identification of more and more contaminants, rapid growth of population and industrial activities, and diminishing availability of water resources.

4. Emerging Technologies- the technique of ultrasound has received much attention as an advanced oxidation process for treating wastewater. When ultrasound is combined with other AOPs, the combination would lead to faster degradation rates when compared to either method alone.

Conventional biological processes often do not provide satisfactory results for the treatment of wastewater from the pharmaceutical industry, due to toxicity. An alternative treatment approach that has recently been adopted is a combination of advanced oxidation processes and biological treatments (Oller et al., 2011). These processes are well known for their capacity of partially or completely mineralising organic contaminants, although their practical large scale applications are limited by their high costs, mainly due to energy consumption (radiation, ozone, etc.) and the need of chemical reagents (catalysts and oxidizers) (Muñoz et al., 2008).

The study and treatment of wastewater from the pharmaceutical industry is a complex and not an easy process. It has multiple organic chemical compounds that differ in all physical and chemical qualities, e.g. wastewater from manufacturing antibiotics is different from wastewater from manufacturing aspirin. Therefore it can be said that every medicine factory wastewater component differs from any other manufacturing plant wastewater and any person can imagine the amount of organic compound quantities that end up in the wastewater from pharmaceutical plants.

The current study focuses only on one specific organic chemical compound that is produced in most pharmaceutical plants. One of the most common chemical compounds is antibiotic. Although there are several types of antibiotics produced daily and even there are a hundred kinds of it, but here the study will focus only on one type known as amoxicillin antibiotics. Amoxicillin was chosen as an example for this study since its removal or treatment in wastewater produced compounds that are known about their impact on 
both human and environment even in very small amounts of concentration as parts per million (Gulkowska et al., 2008; Huber et al., 2003; Kümmerer et al., 2000; Migliore et al., 1997).

Amoxicillin is related to penicillin, which was first discovered by Sir Alexander Fleming in 1928 when he noticed it being produced by the mold Penicilliumnotatum. However, amoxicillin is an artificially altered (semisynthetic) variant of penicillin, and was first made in 1972. The whole point of converting penicillin into amoxicillin is that the latter is more effective at treating disease. Amoxicillin is used to treat many different types of infections caused by bacteria, such as ear infections, bladder infections, pneumonia, gonorrhea, and E. coli or salmonella infection. Amoxicillin is also sometimes used together with another antibiotic called clarithromycin (Biaxin).

Amoxicillin, with molecular formula shown in Fig. 1, is a white or almost white, crystalline powder, slightly soluble in water as shown in Table 1, very slightly soluble in alcohol, practically insoluble in fatty oils. It dissolves in dilute acids and dilute solutions of alkali hydroxide.

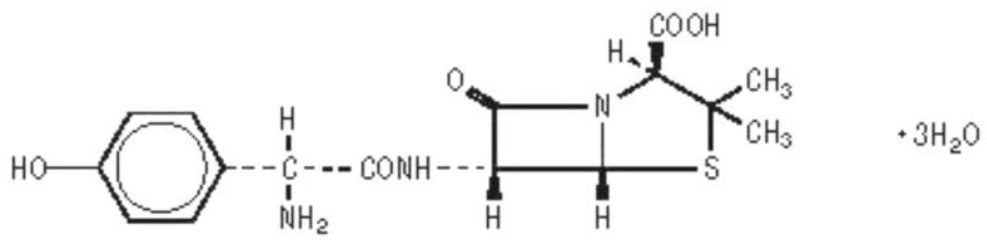

Figure 1. Amoxicillin trihydrate (Molecular formula: C16H19N3O5S, 3H2O)

Amoxicillin does not actually kill bacteria, but instead it prevents them from multiplying, thus, making it easier for the immune system to wipe out the infection. It does this by stopping the new bacteria from forming their cell walls, which are necessary to avoid the contents of the bacterial cell from spewing out into its surroundings. The result of all this is that the infection gradually dies out from the lack of a new generation to replace the old one.

The mechanism by which it prevents the cell walls from forming is based on what is known as the receptor concept. This is where a drug binds to a receptor on the outside of the cell, activating it, thereby causing changes in the cell. In the case of amoxicillin, the receptor is a penicillin binding protein (PBP) on the cell wall of the bacteria. When amoxicillin attaches itself to the PBP, it causes a halt in the production of one of the ingredients of the cell wall, peptidoglycan. Peptidoglycan provides the cell wall with stability, and a lack of it weakens the cell wall to the point of collapse. Altogether, this causes the bacterial cell to split and fall apart.

Table 1. Physical and chemical properties of Amoxicillin

Physical state white to off-white crystalline powder.

\begin{tabular}{ll}
\hline Molecular weight & 419.4 \\
\hline Melting point & $194^{\circ} \mathrm{C}$. \\
\hline Boiling point & $743.2^{\circ} \mathrm{C}$. \\
\hline Density & $0.8 \mathrm{~g} \mathrm{ml}^{-1}$ \\
\hline Solubility in water & $4 \mathrm{~g} \mathrm{ml}^{-1}$ \\
\hline pH & $3.5-5.5$ \\
\hline
\end{tabular}

Stability Stable under ordinary conditions

Introducing the ultrasound in the reaction system for antibiotics removal will play a great role in creating the transient cavitation which will provide turbulent flow conditions within the reactor. The overall mass transfer of reactants and byproducts between the liquid phase and the catalyst surface will be greater than the conventional reaction. Therefore, ultrasound enhanced various advanced oxidation processes including 
catalytic degradation of a wide variety of pollutants (Shukla et al., 2010; Chand et al., 2009; Matouq et al., 2008; David, 2009; Manariotis et al., 2011).

This study aims to examine the possibility of using ultrasound wave technology in wastewater treatment process in industrial plants particularly from pharmaceutical plants. The reactor was specifically designed and built to conduct this study. The reactor was used to study the possibility of oxidation of antibiotics namely amoxicillin contained in wastewater of pharmaceutical plants. The study used a simulated wastewater containing certain proportions of amoxicillin antibiotic with specific concentrations of 50 and $100 \mathrm{ppm}$, to study the impact of ultrasound waves on its oxidation (degradation).

In order to enhance the reaction process a strong oxidizer namely hydrogen peroxide was introduced. The study focused on both the effect of ultrasound on the reaction process in the presence of hydrogen peroxide in different concentrations, and without ultrasound waves at the same reaction conditions. According to literature the process of using ultrasound with strong oxidizers for antibiotics still has not been investigated with high frequency waves $(2.4 \mathrm{MHz})$. The objectives of this study were:

(1) to investigate the decomposition of amoxicillin in aqueous solutions using various doses of hydrogen peroxide under ultrasound irradiation, and

(2) to study the effects of different operating conditions, such as reactant concentration and volume, on the removal efficiency of amoxicillin.

\section{Materials and Chemicals}

Amoxicillin was obtained from Local Jordanian Pharmaceutical in powder form. Acetonitrile for HPCL obtained from VWR. Hydrogen peroxide $\mathrm{H}_{2} \mathrm{O}_{2} 35 \%$ obtained from Riedel-de Haen

\subsection{Experimental Set-up}

The experimental apparatus shown in Fig. 2, consists of a cylindrical vessel with $44 \mathrm{~mm}$ inside diameter and $270 \mathrm{~mm}$ height.

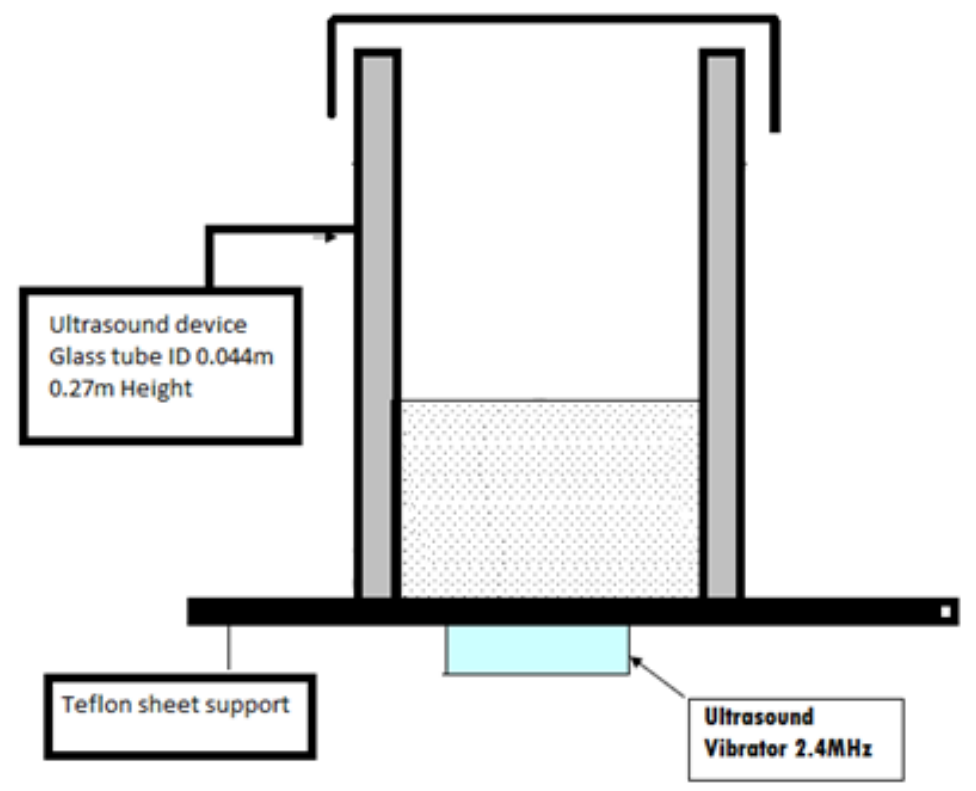

Figure 2. Experimental setup for ultrasound reactor. 
A cover was attached to the cylindrical vessel at the upper side, and was kept close in all experimental works, to prevent any mist of amoxicillin in the form of vapor from leaking to the atmosphere. An electrical source with variable voltage supply ranged from 0 to 40 volts was attached to the apparatus. The electrical supply was also adjusted to control the electrical current source from 0 to $600 \mathrm{~mA}$. All experiments were conducted at 24 volts and $500 \mathrm{~mA}$, according to the specified conditions by the manufacturer of the ultrasound wave device generator. The ultrasonic vibrator comprised of $20 \mathrm{~mm}$ diameter transducer, which contains piezoceramics (sandwich) with titanium end masses leading the face from which the ultrasonic is emitted. It has a frequency of $2.4 \mathrm{MHz}$ and electric input power $9.5 \mathrm{Watt}$, and it is supplied by Honda Electronics Co. Ltd., of Japan, type HM-2412.

\subsection{Methods}

Samples were prepared by taking a measured weight powder of amoxicillin and dissolved in distillate water to prepare a stock solution with a concentration of $5000 \mathrm{ppm}$. The solution kept in refrigerator for conducting experimental works. The stock solution was discarded after two weeks and a new stock solution was prepared in order to eliminate any chance of natural oxidation of antibiotic which may have its effect on experimental results. From this stock solution samples were prepared at concentrations 50 and 100 ppm by simple dilution with distillate water.

In this study, the ultrasound wave device was used in the presence of hydrogen peroxide $50 \%\left(\mathrm{H}_{2} \mathrm{O}_{2}\right)$ to enhance the oxidation (degradation) process with high frequency waves. Different $\mathrm{H}_{2} \mathrm{O}_{2}$ volumes were added to solution just before the initiation of the experiment. The $\mathrm{H}_{2} \mathrm{O}_{2}$ volumes selected were 5, 2, 1, and $0.1 \mathrm{ml}$ and were added at time zero of the reaction. A measured volume of the stock solution of amoxicillin of $50 \mathrm{ml}$ was fixed as standard conditions for solution placed inside the reactor, while some other experiments were conducted at different solution volumes of 40 and $60 \mathrm{ml}$.

A $50 \mathrm{ml}$ sample of amoxicillin with $100 \mathrm{ppm}$ was placed in ultrasonic reactor and $5 \mathrm{ml}$ of $\mathrm{H}_{2} \mathrm{O}_{2}$ were added inside the reactor and was irradiated for 30,60, and $90 \mathrm{~min}$. A sample was collected at the end of the reaction interval time and analyzed using high pressure liquid chromatography (HPLC) type Shimadzu LC-4A Liquid Chromatography using acetonitrile and distilled water (50/50\%) as mobile phase. Column type used here in this analysis is Hypersil C18, $5 \mu \mathrm{m}$ particle size, $25 \mathrm{~cm}$ length, and $4 \mathrm{~mm}$ diameter. Detector type PU4020, uses UV at $254 \mathrm{~nm}$ wavelength. All analysis is performed at room temperature. The same condition was repeated with different $\mathrm{H}_{2} \mathrm{O}_{2}$ volumes of 2,1 , and $0.1 \mathrm{ml}$ and amoxicillin solution at $50 \mathrm{ppm}$.

Two different volumes of amoxicillin solution placed inside the reactor 40 and $60 \mathrm{ml}$ with the fixed concentration of $100 \mathrm{ppm}$ to study the effect of reactant volume on reaction kinetics, keeping the concentration of $\mathrm{H}_{2} \mathrm{O}_{2}$ at 5 and $2 \mathrm{ml}$ only at different time of irradiation i.e., 30, 60, and 90 min. Table 2 summarizes the experimental conditions

Table 2. Experimental conditions

\begin{tabular}{ll}
\hline Time of ultrasound irradiation $(\mathrm{min})$ & $30,60,90$ \\
\hline Ultrasound wave frequency $(\mathrm{MHz})$ & 2.4 \\
\hline Initial volume of Hydrogen peroxide $(\mathrm{ml})$ & $5,2,1,0.1$ \\
\hline Initial concentration of amoxicillin $(\mathrm{ppm})$ & 100,50 \\
\hline Initial solution mixture volume $(\mathrm{ml})$ & $40,50,60$ \\
\hline
\end{tabular}

\section{Results and Discussion}

Before conducting any experimental work with hydrogen peroxide, different runs were conducted and the mixture was exposes only to ultrasound irradiation at $2.4 \mathrm{MHz}$. The concentration of amoxicillin was fixed at $50 \mathrm{ppm}$ for 30,60, and 90 min but no degradation has occurred. The concentration of amoxicillin has not 
changed and stays constant. This means that ultrasound alone is not sufficient enough to degrade the amoxicillin at this wavelength. Therefore, hydrogen peroxide was chosen in order to compare the degradation without and with ultrasound. The following section discusses the main output of these experiments.

\subsection{Effect of $\mathrm{H}_{2} \mathrm{O}_{2}$ and ultrasound on amoxicillin degradation}

Fig. 3 shows the results of oxidizing a $50 \mathrm{ppm}$ solution of amoxicillin after the addition of four different hydrogen peroxide doses $(5,2,1$ and $0.1 \mathrm{ml})$. At the same time interval, the amount of amoxicillin degraded is increasing with increasing peroxide dose. The lowest dose of peroxide $0.1 \mathrm{ml}$ gives the lowest degradation after it is exposed to ultrasound irradiation. The figure also indicates that the degradation profile increase with increasing time. It is also clear that the degradation of amoxicillin can reach about $70 \%$ when the peroxide dose is $5 \mathrm{ml}$ after only $90 \mathrm{~min}$.

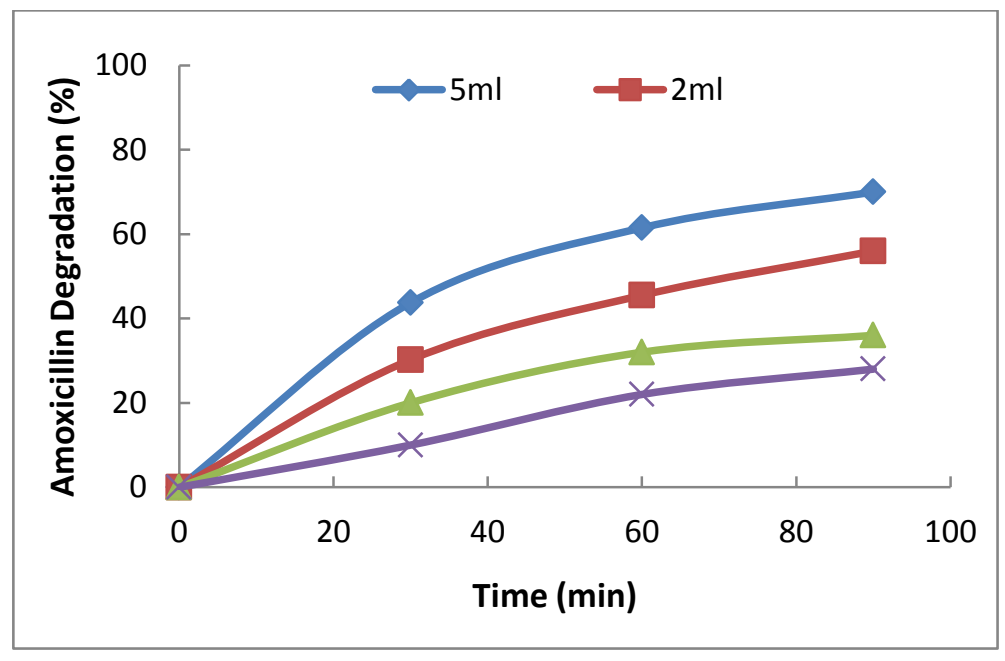

Figure 3. Degradation of amoxicillin at $50 \mathrm{ppm}$ initial concentration after the addition of different peroxide doses using $2.4 \mathrm{MHz}$ ultrasound waves.

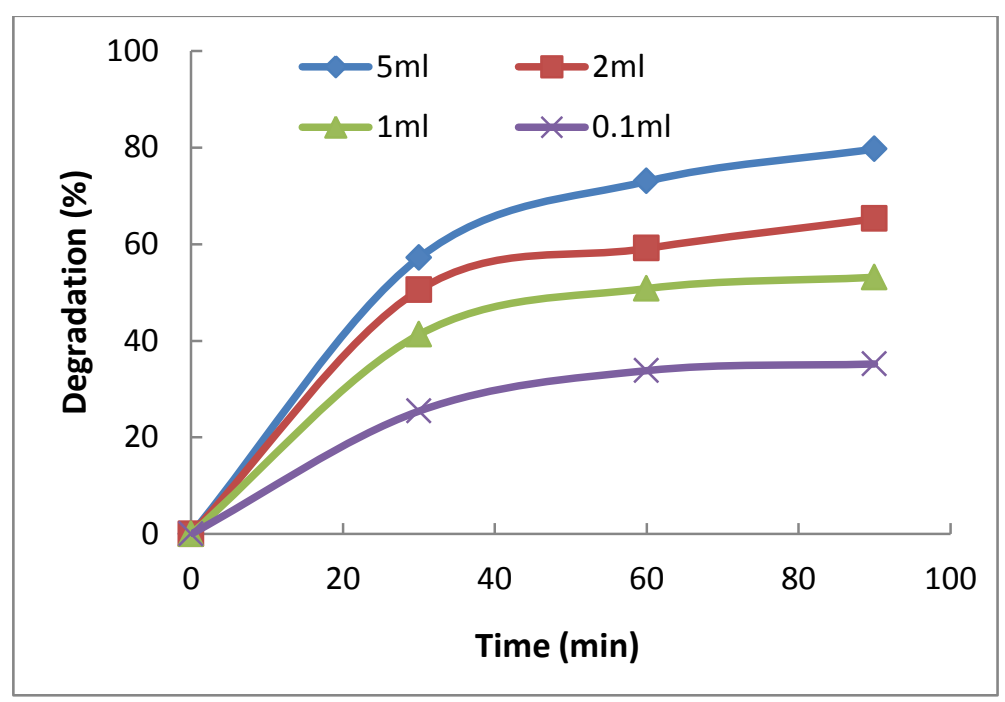

Figure 4. Degradation of amoxicillin at $100 \mathrm{ppm}$ initial concentration after the addition of different peroxide doses using $2.4 \mathrm{MHz}$ ultrasound waves. 
Fig. 4 shows the results obtained when the concentration of amoxicillin has doubled to $100 \mathrm{ppm}$ with the same conditions of $2.4 \mathrm{MHz}$ and different doses of peroxides. The degradation profiles are increasing with increasing peroxide doses and time. This means the amoxicillin degradation is enhanced in both the ultrasound and peroxides presences.

In order to study the effect of ultrasound on amoxicillin degradation the same experimental conditions were repeated without any ultrasound waves (Figs. 5 and 6). According to these figures, the degradation percentage is lower than that in those experiments conducted in the presence of ultrasound. At both concentrations, the maximum value of amoxicillin degradation is reached after $30 \mathrm{~min}$ and is around $30 \%$; no more degradation is noticed after that time. This clearly indicates that introducing the ultrasound enhanced the degradation process more than twice compared with the results of previous experiments at the same conditions.

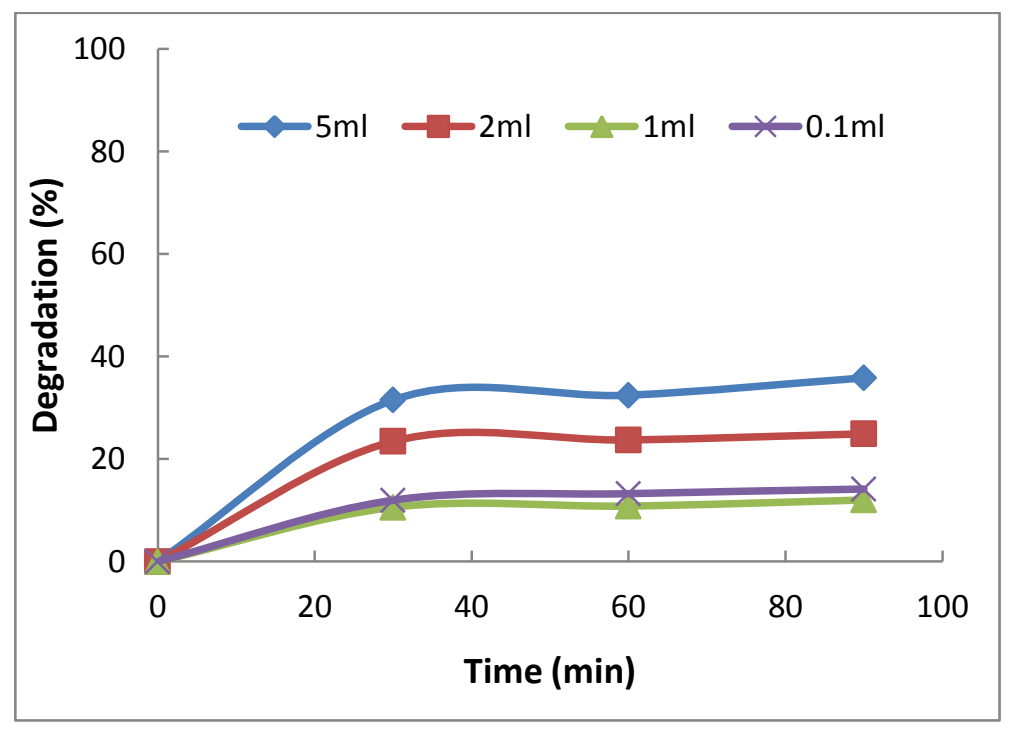

Figure 5. Degradation of amoxicillin at $100 \mathrm{ppm}$ initial concentration after the addition of different peroxide doses using no ultrasound waves.

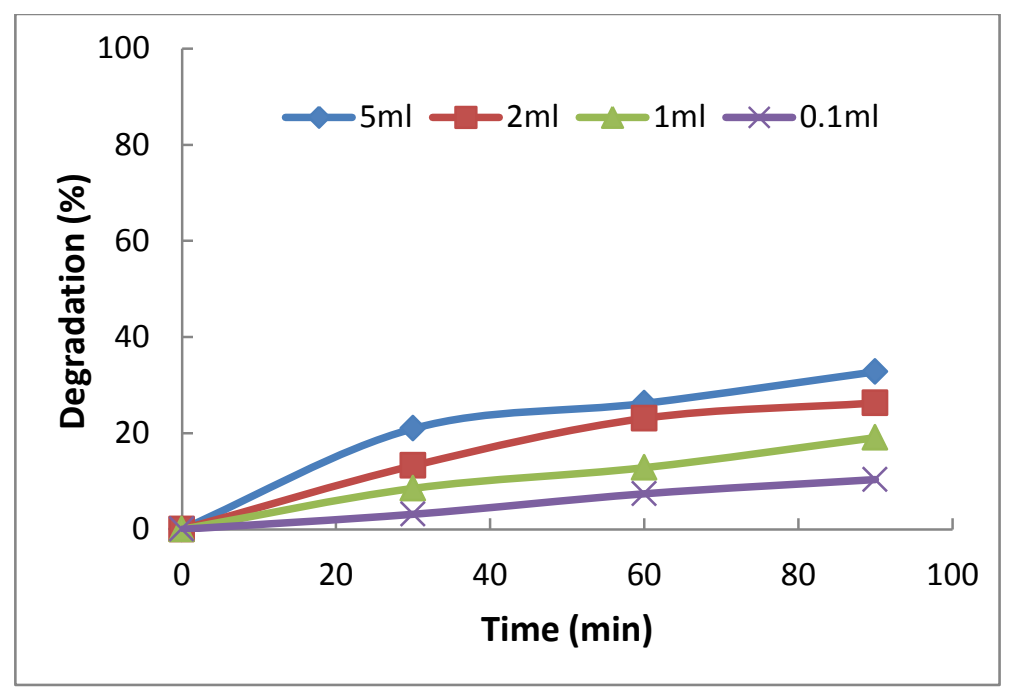

Figure 6. Degradation of amoxicillin at $50 \mathrm{ppm}$ initial concentration after the addition of different peroxide doses using no ultrasound waves. 


\subsection{Effect of liquid volume change on amoxicillin degradation}

Figs. 7 and 8 show the results obtained after changing the liquid solution volume inside the reactors at three different selected volumes 40,50, and $60 \mathrm{ml}$. The peroxides dose is fixed at $2 \mathrm{ml}$ for both initial concentration of amoxicillin of 50 and $100 \mathrm{ppm}$. It is clear from these figures that the degradation is higher when the liquid volume is lower. This may be attributed to the liquid height above the ultrasound cell. As much as liquid volume increases the solution pressure head above the cell will prevent the vibration of cell from producing proper waves to degrade the amoxicillin.

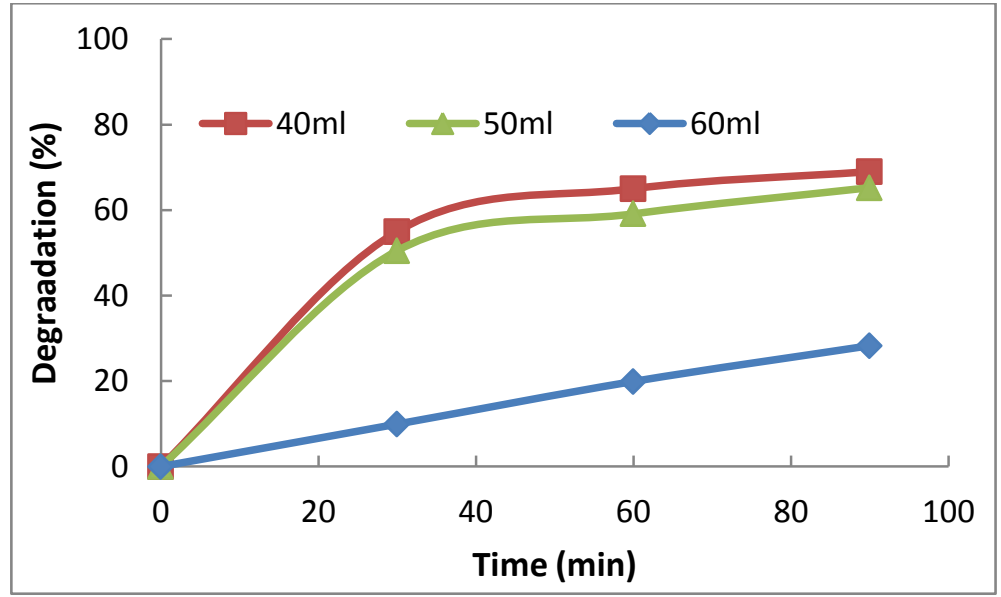

Figure 7. Degradation of amoxicillin at diffent liquid solution volumes inside reactor at $100 \mathrm{ppm}$ initial concentration and $2 \mathrm{ml}$ peroxide dose.

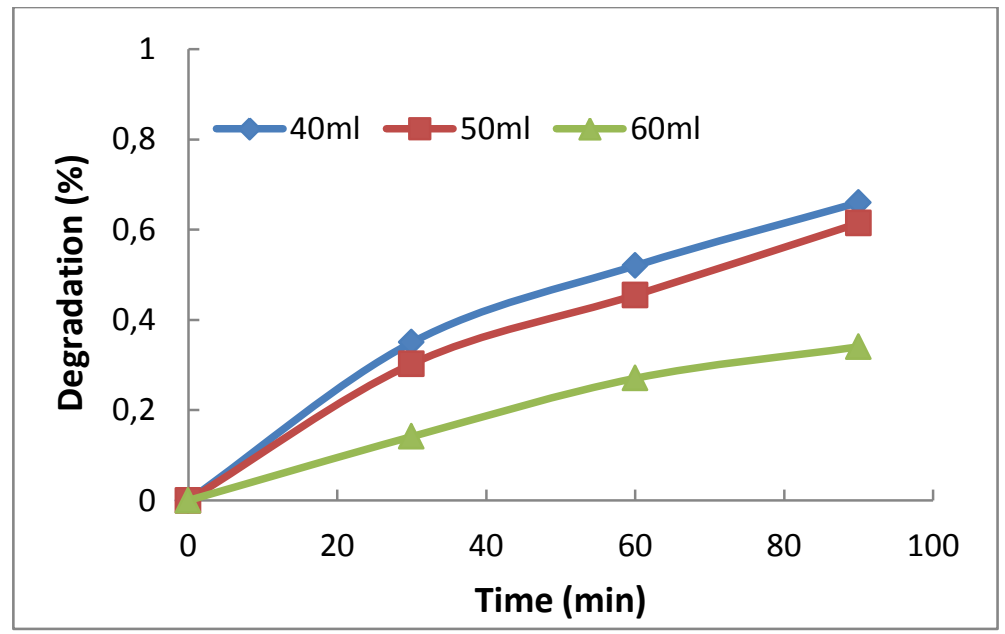

Figure 8. Degradation of amoxicillin at diffent liquid solution volume inside reactor at $50 \mathrm{ppm}$ initial concentration and $2 \mathrm{ml}$ peroxide dose

\section{Conclusions}

This is the first study that uses high-frequency ultrasound for the degradation of amoxicillin. Also, most of the literature references are talking about ultrasound bath, but not ultrasound cell. Ultrasound alone was not sufficient to degrade the antibiotic and another oxidant was needed. The degradation of amoxicillin in the presence of hydrogen peroxide and high-frequency ultrasound was successfully obtained. The results of the present study show that the degradation of antibiotics, namely amoxicillin has been enhanced by highfrequency ultrasound waves. The interesting point of this research that the introduction of ultrasound alone 
was not able to degrade amoxicillin, was reversed when a strong oxidant like hydrogen peroxide was used. The degradation process has been improved almost twice compared to that of hydrogen peroxide only. The rate of degradation of about $70 \%$ is achieved within $90 \mathrm{~min}$. Changing amoxicillin solution volume inside the reactor has a significant effect on the degradation rate; mainly, increasing the solution volume will decrease the degradation rate. This can be attributed to the solution volume head over the cell of ultrasound that has an effect on ultrasound cell vibration and reduces the waves produced during the degradation process.

\section{Acknowledgment}

This work has been carried out during sabbatical leave granted to Matouq Mohammed, from Al-Balqa' Applied University (BAU) during the academic year 2011/2012. Authors are also thankful to Mr Nabih Irqsousi for his great help in analysis conducted in his laboratory.

\section{References:}

Chand R., N.H. Ince, P.R. Gogate and D.H. Bremner (2009), Phenol Degradation using 20, 300, and 520 kHZ Ultrasoniic rector with hydrogen peroxide, ozone and zero valent metals, Sep. Purif. Technol., 67, 103.

da Silva M.F., Tiago I., Verissimo A., Boaventura R.A.R., Nunes O.C. and Manaia C.M. (2006), Antibiotic resistance of enterococci and related bacteria in an urban wastewater treatment plant, FEMS Microbiology Ecology, 55(2), 322-329.

David B. (2009), Sonochemical degradation of PAH in aqueous solution. Part I: mono-component PAH solution, Ultrason. Sonochem., 16, 260-265.

Gulkowska A., Leung H.W., So M.K., Taniyasu S., Yamashita N., Yeung L.W.Y. Richardson B.J., Lei A.P., Giesya J.P. and Lam P.K.S. (2008), Removal of antibiotics from wastewater by sewage treatment facilities in Hong Kong and Shenzhen, China, Water Research, 42(1-2), 395-403.

Huber M.M., Canonica S., Park G.Y. and von Gunten U. (2003), Oxidation of pharmaceuticals during ozonation and advanced oxidation processes, Environmental Science and Technology, 37(5), 1016-1024.

Kümmerer K., Al-Ahmad A. and Mersch-Sundermann V. (2000), Biodegradability of some antibiotics, elimination of the genotoxicity and affection of wastewater bacteria in a simple test, Chemosphere, 40(7), 701-710.

Manariotis I.D., Karapanagioti H.K. and Chrysikopoulos C.V. (2011), Degradation of PAHs by high frequency ultrasound, Water Res., 45, 2587-2594.

Matouq M.A., Al-Anber Z.A., Tagawa T., Aljbour S. and Al-Shannag M. (2008), Degra-dation of dissolved diazinon pesticide in water using the high frequency ofultrasound wave, Ultrason. Sonochem., 15, 869-874.

Migliore L., Civitareale C., Brambilla G. and Di Delupis G.D. (1997), Toxicity of several important agricultural antibiotics to Artemia, Water Research, 31(7), 1801-1806.

Muñoz I., Malato S., Rodríguez A. and Doménech X. (2008), Integration of environmental and economic performance of processes. Case study on advanced oxidation processes for wastewater treatment, J. Adv. Oxid. Technol., 11, 270-275.

Oller I., Malato S. and Sánchez-Pérez J.A. (2011), Combination of Advanced Oxidation Processes and biological treatments for wastewater decontamination - A review., Sci. Total Environ., 409(20), 4141-4166.

Shukla P.R., Wang S.,Sun H.,Ang H.M. and Tadé M. (2010), Activated carbon supported cobalt catalysts for advanced oxidation of organic contaminants in aqueous solution, Appl. Catal. B: Environ., 100, 529-534. 